\title{
Melted delivery hose - a complication of a heated humidifier
}

The polyvinylchloride delivery hase of a Fisher \& Paykel dua! sevo heated antasthetic humidifier was melted by the intraluminal hose heater, causing a major leakage of anaesthetic gases during a surgical procedure. Under experimental condi. tions, melting could be reproduced using polyvinylchloride but nor polyester elastomer tubings. Only tubings made of material. with high melting point should be used as delivery hose in heated humidifiers with hose heaters

A previously unreported complication of melted anaesthetic hose occurred when a heated humidifier, with dual servo control of heaters in both the water reservoir and the delivery hose, was used. This complication was reproduced experimentally.

\section{Case report}

A healthy 11 year old boy was burned in the left leg while playing with gasoline. He came to the operating room eight days after the accident for surgical debridement and harvesting skin graft. He weighed $27 \mathrm{~kg}$.

The operating room temperature was $24^{\circ} \mathrm{C}$. A fluid warmer was used to warm the intravenous fluids. A Fisher \& Paykel (F \& P) Dual Servo Heated Humidifier for Anaesthesia, Model MR620, was incorporated in the inspiratory limb of the circle system of a Dräger anaesthetic machine. The humidifier had a heater for the water reservoir, and an additional intraluminal heater in the delivery hose.

\section{Key words}

COMPLICATIONS: melted humidifier hose; EQUIPMENT: heated humidifier; TUBING: polyvinylchloride, autoclavable

From the Department of Anaesthesia, Faculty of Medicine, University of British Columbia, Vancouver, British Columbia

Address correspondence to: Dr. David H.W. Wong, Department of Anaesthesia, Vancouver General Hospital, Room 3200, 910 West 10th Avenue, Vancouver, British Columbia, VSZ 4E3.
Anaesthesia was induced with thiopentone and atracurium. A circle absorber anaesthetic circuit was connected to the tracheal tube. The inspiratory and the expiratory hoses were tucked under the edge of the patient's pillow to minimize the pull on the tracheal tube by the weight of the hoses. Anaesthesia was maintained with fentanyl, isoflurane, nitrous oxide and oxygen. The fresh anaesthetic gas flow consisted of $3 \mathrm{~L} \cdot \mathrm{min}^{-1} \mathrm{~N}_{2} \mathrm{O}, 2 \mathrm{~L} \cdot \mathrm{min}^{-1} \mathrm{O}_{2}$, and 1.5 per cent isoflurane. The temperature of the humidifier was set at $39^{\circ} \mathrm{C}$.

Ventilation was controlled using the volume preset, time-cycled Dräger AV-E Anesthesia Ventilator. Tidal volume was $250 \mathrm{ml}$, rate 12 times per minute, with an inspiratory/expiratory ratio of $1: 2$. The end-tidal $\mathrm{CO}_{2}$ level was maintained between 4.26 and $4.52 \mathrm{kPa} \mathrm{(32}$ and $34 \mathrm{mmHg}$ ) as measured by mass spectrometry.

The patient was stable throughout the procedure. About 30 minutes after intubation, a hissing noise was heard coming from the anaesthetic circuit. The connections of the hoses to the machine and to the tracheal tube were found to be secured. Within seconds, the disconnection alarm sounded. The maximal circuit pressure had dropped from 1.37 to $0.59 \mathrm{kPa}\left(14\right.$ to $\left.6 \mathrm{cmH}_{2} \mathrm{O}\right)$. At this time, it was recognised that the anaesthetic gases were leaking from the delivery hose of the humidifier. The hose had been melted by the heater wire (Figure 1). The humidifier panel indicated that the temperature at the patient end of the delivery hose was $37.2^{\circ} \mathrm{C}$. The humidifier was immediately bypassed, and the circle system re-established without compromising the patient's ventilation. The rest of the procedure was uneventful.

The polyvinylchloride corrugated delivery hose, 105 $\mathrm{cm}$ long and $2.5 \mathrm{~cm}$ in diameter, housed an insulated heater wire which made a hairpin bend at $87 \mathrm{~cm}$ from the humidifier unit. The hose was melted by the intraluminal heater wire, producing a hole $5 \mathrm{~cm}$ long. In addition, thermal markings could be seen for a length of $12 \mathrm{~cm}$ proximal to this opening.

It was learned that four cases of melted delivery hose had occurred within a period of three weeks in the same hospital. Experiments were therefore conducted in order to reproduce this complication and to find out the cause of melting of the hoses. A further experiment was done to 


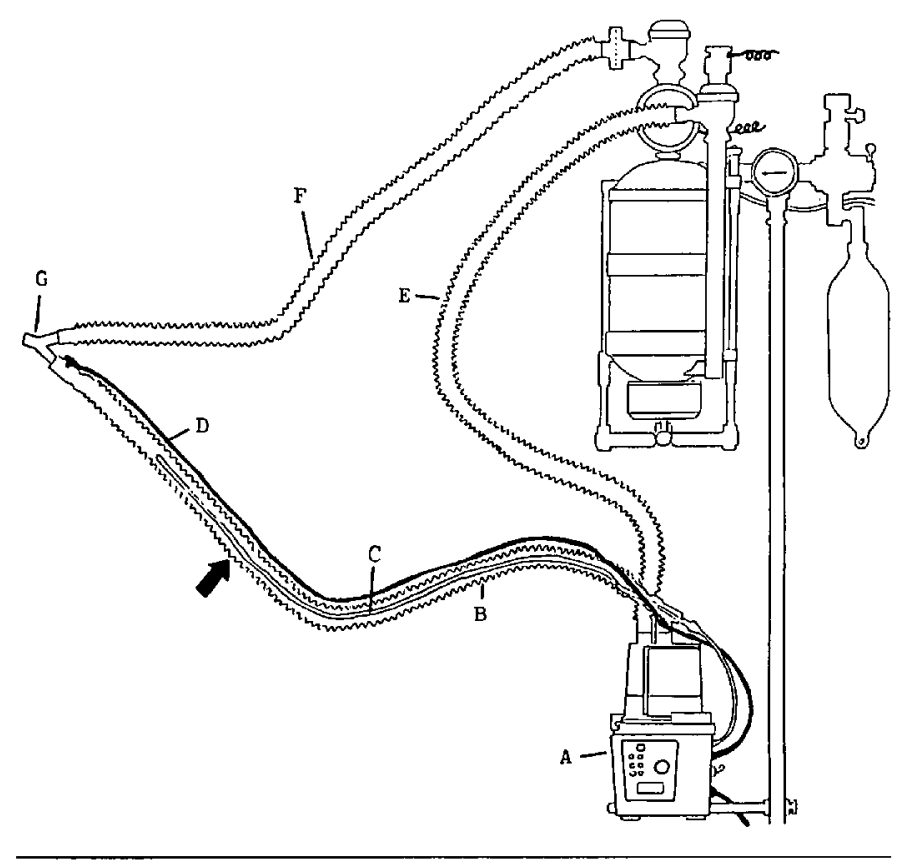

FIGURE 1 Fisher \& Paykel dual servo heated humidifier in use with the circle absorber anaesthetic circuit. Arrow indicates the location of melting in the delivery hose in the reported case. A -

$\mathrm{F} \& \mathrm{P}$ humidifier, B - delivery hose, $\mathrm{C}$ - hose heater, $\mathrm{D}$ - temperature probe, E - inspiratory tubing, $\mathrm{F}$ - expiratory tubing, $\mathrm{G}-\mathrm{Y}$-connector to patient.

ensure that the complication would not occur after the problem was corrected.

\section{Experimental study}

The same basic setup was used in all experiments. A Narkomed 2A anaesthetic machine (North America Dräger) with a built-in Dräger AV-E Anesthesia Ventilator was used. The inspiratory limb of the circle absorber circuit was fitted with a F \& P Dual Servo Heated Humidifier for Anaesthesia, Model MR620. In Experiments \#1 and \#2, a clear polyvinylchloride corrugated tubing was used as delivery hose from the humidifier. In Experiment \#3, this was replaced by a tubing made of material with high melting point.

The humidifier reservoir was filled with $250 \mathrm{ml}$ of sterile water, and the temperature control was set at $39^{\circ} \mathrm{C}$. The temperature inside the delivery hose was monitored at two sites using two Yellow Springs Instrument (YSI) digital thermometers, one at the midpoint adjacent to the heater wire, and the other at the patient end close to the temperature sensor of the humidifier.

A three-litre bag was fitted onto the $Y$ connector of the circuit to mimic the patient's lungs. The humidifier heater was turned on after ventilation had commenced.

\section{Experiment \#1}

To try to reproduce the complication with the same fresh gas flows and ventilation as used in the case reported.

The flowmeter settings were $2 \mathrm{~L}-\mathrm{min}^{-1} \mathrm{O}_{2}$ and $3 \mathrm{~L} \cdot \mathrm{min}^{-1} \mathrm{~N}_{2} \mathrm{O}$. The tidal volume was set at $250 \mathrm{ml}$, at a rate of 12 times per minute, with an inspiratory/expiratory ratio of $1: 2$.

It was found that the temperature at the patient end of the delivery hose (as displayed by the humidifier panel and measured by the YSI digital thermometer) reached $37^{\circ} \mathrm{C}$ in 14 minutes, and stayed within half a degree difference from this value for the rest of the experiment. The temperature at midway down the delivery hose reached $43^{\circ} \mathrm{C}$ (the upper limit of the YSI thermometer) within five minutes.

The temperature of the humidified gases from the humidifier was well maintained, and there was no sign of thermal damage to the delivery hose after two hours of continuous use. 
A

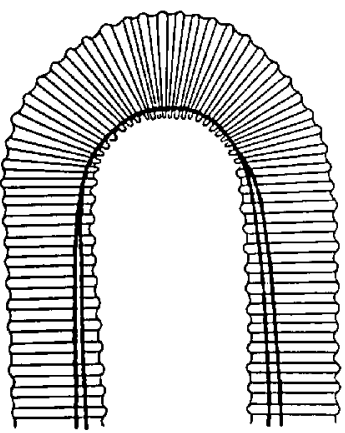

B

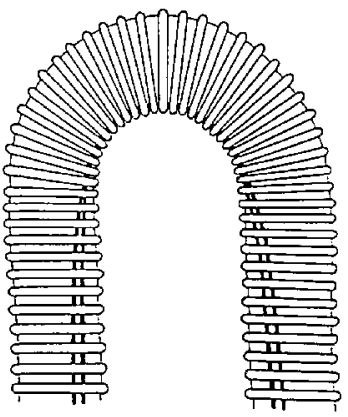

FIGURE 2 The hose heater wire is shown stretched around a bend of the delivery hose to keep in physical contact with the wall of the hose. A - polyvinylchloride tubing. B - autoclavable Hytrel tubing.

\section{Experiment \#2}

To try to reproduce the complication by deliberately keeping the heater wire in contact with the wall of the hose.

The delivery hose was stretched and bent at its midpoint, and the hose heater wire was stretched and kept in physical contact with the wall of the hose (Figure 2, A).

Fresh gas flows were $2 \mathrm{~L} \cdot \mathrm{min}^{-1} \mathrm{O}_{2}$ and $3 \mathrm{~L} \cdot \mathrm{min}^{-1}$ $\mathrm{N}_{2} \mathrm{O}$. Tidal volume was $800 \mathrm{ml}$, rate 10 times per minute, and inspiratory/expiratory ratio of $1: 2$.

The pattern of temperature rise at the patient end of the delivery hose was similar to that in Experiment \#1. The temperature of the hose at the bend reached $43^{\circ} \mathrm{C}$ within 5 minutes. The delivery hose melted at the site of contact with the heater wire one hour 19 minutes after the humidifier was turned on, triggering the disconnection alarm.

\section{Experiment \#3}

To try to reproduce the complication using a delivery hose made of materials with high melting point, and keeping the heater wire in contact with the wall of the hose.

A Hytrel Tubing (A-M Systems Inc., Everett, Washington), instead of the polyvinylchloride corrugated tubing, was used as the delivery hose from the humidifier.

The heater wire was stretched and kept in contact with the wall of the delivery hose in the same manner as in Experiment \#2 (Figure 2, B).

Fresh gas flows were $0.5 \mathrm{~L} \cdot \mathrm{min}^{-1} \mathrm{O}_{2}$ and $0.5 \mathrm{~L} \cdot \mathrm{min}^{-1}$ $\mathrm{N}_{2} \mathrm{O}$. Tidal volume was $500 \mathrm{ml}$, rate $8 \cdot \mathrm{min}^{-1}, \mathrm{I} / \mathrm{E}$ ratio 1:2.

The temperature of the hose at the bend reached $43^{\circ} \mathrm{C}$ within five minutes. There was no sign of melting after 5 hours of continuous use.

\section{Discussion}

The F \& P Dual Servo Heated Respiratory Humidifiers ${ }^{1}$ (Auckland, New Zealand) are useful for humidifying anaesthetic gases. A heater plate in the base module heats the water reservoir, and an intraluminal hose heater keeps the temperature in the delivey hose above the dew point. This maintains the temperature and water saturation of the inspired gases without condensation in the system. A microprocessor-based Dual Servo temperature controller monitors the temperature at both ends of the delivery hose, and automatically regulates the heater plate and hose heater to ensure that the desired delivery temperature is maintained with a minimum of condensation. A comprehensive alarm system is built in for maximum patient safety.

The F \& P humidifier has been used satisfactorily in neonates, infants and children. ${ }^{2}$ Small ventilatory volumes and low fresh gas flows do not affect the performance and safety of the unit. Temperature fluctuations, however, can occur with changing flow rates and following interrupted flow. ${ }^{3,4}$ The author is unaware of any published report in the anesthetic literature of the hose having been melted by the hose heater wire. Indeed, the Grant humidifier has a heating element incorporated into the wall of the delivery hose.

The F \& P Heated Humidifier, Model MR500, has been in use in our hospital for two years. Its performance is reliable and safe. The F \& P Humidifier, Model MR620, designed for anaesthesia use, was acquired recently to replace the older model, and was used in the reported case. The electrical specifications for this model are $115 \mathrm{~V}, 60 \mathrm{~Hz}$ and $1.5 \mathrm{~A}$. The water heater is $120 \mathrm{~W}$, and the hose heater capacity is $45 \mathrm{~W}$. In the earlier units, the hose heater capacity was $25 \mathrm{~W}$. 
The company was contacted by telephone after four cascs of melted delivery hose had occurred. According to the spokesman, this had never been reported. The biomedical engineering department of our hospital was notified of the complication. It was pointed out that the operating manual did mention the use of autoclavable delivery hose. Once the problem was identified, the polyvinylchloride tubing was replaced by Hytrel tubings for all $\mathrm{F} \& \mathrm{P}$ Heated Humidifiers in our department. Hytrel is a polyester elastomer made by DuPont Compaay, and may be sterilized at $270^{\circ} \mathrm{F}\left(132^{\circ} \mathrm{C}\right)$ in an autoclave. There has not been any further incident of melted hose.

It was interesting that polyvinylchloride tubing had been in use as delivery hose for the F \& P Humidifiers for at least two years without problems. This was the same tubing used in the circle absorber circuit of our anaesthetic machines. The exact melting point is not known, but generally these tubings can withstand temperatures up to at least $60^{\circ} \mathrm{C}$. Perhaps the reason that melting did not occur before was that the hose heater capacity was lower at $25 \mathrm{~W}$ in the older Model MR500, as compared to $45 \mathrm{~W}$ in the new Model MR620.

The hose heater wire normally lies freely inside the delivery hose. The temperature at the patient end is continuously monitored, and servo control with alarm is built into the system. This temperature would not exceed the level set by the operator, the highest being $40^{\circ} \mathrm{C}$. However, the temperature of the heater wire while in use must be higher than the temperature of the gases at the end of the hose. The ventilating gases serve to dissipate the heat from the heater wire. If the wire is in prolonged physical contact with the hose, it can melt the hose. By stretching the heater wire inside a loop of hose, it was demonstrated, in Experiment \#2, that prolonged contact can melt a polyvinylchloridc tubing. This was what happened in the reported case where the hoses were stretched when tucked under the pillow

In Experiment \#3, physical contact between the heater wire and the autoclavable Hytrel tubing did not produce thermal darnage to the tubing despite prolonged operation with low fresh gas flows

Melting of the delivery hose would not have occurred had the recommendation of the operating manual been followed properly. Having used the same polyvinylchloride tubing for more than two years, it was the change to a different humidifier model, with a higher heater capacity designed for anaesthesia use, that brought out the hidden problem.

\section{References}

1 Spence M, Melville AW. A new humidifier. Anesthesiology 1972; 36: 89-93.

2 Fisk GC, Vonwiller JB. Experience using the F. \& P. Humidifier for pediatric patients (Correspondence). Anesthesiology 1972; 37: 568 .

3 Steward DJ, Volgyesi GA. Heated humidifiers may deliver hot gases (Abstract). Anesthesiology 1983; 59: A430.

4 Steward DJ, Volgyesi GA. The performance of humidifiers equipped with heated delivery systems (Abstract). Can Anaesth Soc J 1983; 30: S62-S63.

\section{Résumé}

Avec un Fisher \& Paykel double servo hunidificateur anesthésique chauffé on a constaté que le tuyau de sortie avait fondu par le réchaud intra-iuminal du iuyau occasionnan ainsi une faite importante dh gaz anesthésique tors d'une chirurgie. Ce problème était reproduit expérimentalement. Uniquement des tuyaux faits de matériel ayant un point de fusion élevé doivent être utilisés comme tuyaux de sortie dans ces humidificateurs chauffés avec un réchaud intra-luminal. 